\title{
Mulheres de Santa Luzia da Ilha do Baixio na Várzea do Baixo Solimões: modernidade e tradição
}

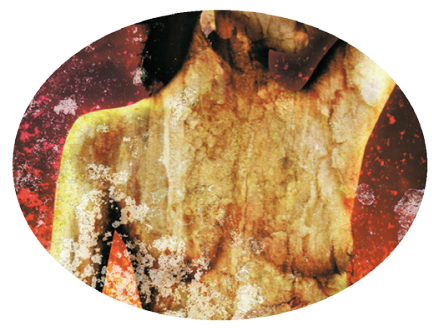

Ana Gouvêa Bocchini*

Kátia Helena Serafina Cruz Schweickardt ${ }^{* *}$

\section{Resumo}

A mulher campesina tem conquistado visibilidade em alguns lugares da Amazônia. Nessa perspectiva, a partir do estudo etnográfico que vem sendo realizado desde 2011 na comunidade Santa Luzia da ilha do Baixio, na várzea do baixo Solimões, Amazonas, pretende-se levar o leitor a uma reflexão sobre o modo de vida da mulher campesina e suas articulações e reconfigurações a partir dos parâmetros da modernidade.

Palavras-chave: relações de gênero; camponês amazônico; etnografia.

\begin{abstract}
The rural woman has gained visibility in some places of the Amazon. In this perspective, from an ethnographic study that has been carried out since 2011 at the community "Santa Luzia da ilha do Baixio", in the floodplain of the Lower Solimões, Amazonas state, the article aims to lead the reader to reflect on the livelihood of rural woman and your joints and reconfigurations from the parameters of modernity.
\end{abstract}

Keywords: gender relations; peasant Amazonian; ethnography.

\footnotetext{
* Mestranda no Programa de Pós-Graduação em Ciências do Ambiente e Sustentabilidade na Amazônia pela Universidade Federal do Amazonas - Ufam. E-mail: anagouveab@gmail.com

*** Doutora em Sociologia e Antropologia pela Universidade Federal do Rio de Janeiro (2010) e mestre em Sociedade e Cultura na Amazônia pela Universidade Federal do Amazonas (2001). Professora-adjunta do Departamento de Ciências Sociais da Universidade Federal do Amazonas. E-mail: katia-helena@uol. com.br
} 


\section{Introdução}

Os modelos de desenvolvimento fundados nos valores da modernidade atravessam o século 20 deixando de lado os grupos sociais que mantêm em seus modos de vida vínculos com costumes e culturas tradicionais. Como contraponto, o discurso em torno das questões ambientais tem trazido à tona formas tradicionais de trabalho, muitas vezes inventadas ou tornadas visíveis com base numa economia que considera o valor dos recursos naturais.

Dentre estes grupos sociais que vêm ganhando destaque nos debates ambientais e mantêm um modo de vida tradicional, estão aqueles que vivem na região amazônica. Atualmente, mesmo que surgido em um interesse internacional a propósito do discurso sobre desenvolvimento sustentável, os camponeses amazônicos vêm ganhando visibilidade, afirmando seu modo de vida e conquistando direitos. A mulher campesina, igualmente, tem conquistado mais espaço em vários pontos da Amazônia pela sua participação na luta por terras, em defesa da floresta e dos recursos naturais. O modo de vida dos camponeses amazônicos, e de modo especial das mulheres, possui uma relação estreita com os rios, onde a várzea é parte importante da sua vida que é intimamente ligada ao movimento das águas.

Nessa perspectiva, com base em um estudo etnográfico que vem sendo realizado desde 2011, com as mulheres da comunidade Santa Luzia da ilha do Baixio, município de Iranduba, na várzea do baixo Solimões, Estado do Amazonas, o artigo pretende levar o leitor a uma reflexão sobre o modo de vida campesino - tradicional - e suas articulações e reconfigurações a partir dos parâmetros da modernidade.

Esta pesquisa usou procedimentos adotados pela sociologia e antropologia. Com uma abordagem qualitativa, utilizou recursos metodológicos combinados: descrição etnográfica, observação participante e realização de entrevistas espontâneas para descrever aspectos do modo de vida das mulheres dessa comunidade.

Clifford (1998) considera a observação participativa um método privilegiado da antropologia, desenvolvido a partir do trabalho de campo, que implica um grau de envolvimento direto e um desarranjo das expectativas pessoais e culturais. É um meio de se produzir conhecimento a partir de um intenso envolvimento intersubjetivo. 
Nesse contato direto com as pessoas, além das observações participativas, foram também realizadas entrevistas com mulheres moradoras da comunidade e, eventualmente, com homens. Tais entrevistas abordam questões sobre seu modo de vida, procurando identificar, em suas narrativas, possíveis relações com a ideia de sustentabilidade. Segundo Pierre Bourdieu, a situação de entrevista constitui, para o pesquisado,

uma situação de comunicação completamente excepcional, livre dos constrangimentos, principalmente temporais, que pesam sobre a maior parte das trocas cotidianas e abrindolhes alternativas que o incitam ou o autorizam a exprimir mal-estares, faltas ou necessidades que ele descobre exprimindo-os, o pesquisador contribui para criar as condições de aparecimento de um discurso extraordinário, que poderia nunca ter tido e que, todavia, já estava lá, esperando suas condições de atualização (BOURDIEU, 2011: 704).

As entrevistas e observações participativas são consideradas as fases de "olhar e ouvir" definidas por Roberto Cardoso de Oliveira em O Trabalho do Antropólogo (2000). São os atos cognitivos mais preliminares no trabalho de campo e, numa segunda etapa, temos "o escrever", que cumpre sua mais alta função cognitiva. Neste momento trazemos os fatos observados (vistos e ouvidos) para o plano do discurso relativizado: ${ }^{1}$

Etnografia é uma descrição densa. O que o etnógrafo enfrenta é uma multiplicidade de estruturas conceptuais complexas, muitas delas sobrepostas ou amarradas umas às outras, que são simultaneamente estranhas, irregulares e inexplícitas, e que ele tem que, de alguma forma, primeiro aprender e depois apresentar. Isso referente às diversas etapas do trabalho de campo: entrevistar informantes, observar rituais, escrever seu diário [...]. Fazer etnografia é como tentar ler um manuscrito estranho, desbotado, cheio de elementos subentendidos, incoerências, enredos suspeitos, comentários tendenciosos (GEERTZ, 1989: 7).

De acordo com Geertz, os “textos” antropológicos são interpretações 
sobre as interpretações nativas, já que os nativos produzem interpretações de sua experiência. Tais textos são "ficções", no sentido de que são "construídos". Esse aspecto resulta em um questionamento constante do pesquisador a respeito dos limites de sua capacidade de conhecer o grupo que estuda e na necessidade de expor, em seu texto, suas dúvidas, perplexidades e os caminhos que levaram a sua interpretação, percebida sempre como parcial e provisória. O estudo etnográfico realizado na comunidade Santa Luzia do Baixio nos possibilitou realizar uma breve descrição de alguns aspectos locais acerca da agricultura familiar, educação, saúde, construções e as relações que mantém com o mundo urbano.

\section{A comunidade Santa Luzia da ilha do Baixio}

Ao longo das calhas dos rios da Amazônia, hoje, os assentamentos humanos ou localidades do interior são conhecidos como comunidades. O termo comunidade possui múltiplos significados, revelando um lugar de gente que se conhece e partilha um mesmo espaço, em seus diversos aspectos:

Ser de uma comunidade é quase como que possuir um sobrenome, ter uma identidade, que significa mais que uma delimitação física [...]. Ser de uma comunidade indica pertencimento a um grupo determinado, e não a outro. É estar vinculado por laços de parentesco e afinidade. É ter relações de vizinhança, que mesmo possuindo semelhanças com as demais comunidades do rio, possuem também várias diferenças [...]. É uma construção social, cuja característica crucial é o fato do pertencimento gerar direitos especiais que os membros partilham entre si, e que não se estendem a quem não pertence à mesma comunidade (SCHWEICKARDT, 2010: 48-49).

Na Amazônia, as comunidades surgiram como tais a partir da década de 1960, principalmente numa iniciativa pastoral da Igreja Católica, e passaram a ser reconhecidas pelo poder público na implantação de algumas obras de infraestrutura.

A comunidade Santa Luzia da ilha do Baixio surgiu no final da década 
de 1940 e hoje é conhecida em sua região por ser uma grande produtora de hortaliças. Os irmãos João e José Alves dos Santos, vindos de Pernambuco como soldados da borracha, decidiram começar uma nova vida na ilha do Baixio:

A mamãe falou para ele (seu pai, Seu João) vim. (...) Aí ele ficou por ali e disse 'eu vou também'. Aí veio os três, né? Veio a mamãe, veio a sogra dele [...]. Eu vim também, né? Só que eu muito novinho, com seis meses. [...] Aí vieram e deste passeio ficaram... não faz muito tempo não, apenas 64 anos! (Entrevista com Lula Filho, comunidade Santa Luzia da ilha do Baixio, 4/11/2011).

Antes de irem para o Baixio, a família morava em Careiro da Várzea, numa região conhecida como Pacatuba, quando ficaram sabendo da ilha do Baixio, uma propriedade particular que o dono estava vendendo ou arrendando para quem quisesse lá morar e trabalhar. A sogra e a cunhada de Seu João começaram a trabalhar em um roçado na área, principalmente com a plantação de juta:

Eu gostei daqui, da localidade. Meu irmão já tinha trabalhado parece que um mês e pouco aí. E viu um lugar bonito. Peguei um pessoal aí que era dono daqui do terreno, né? E queria arrendar, né? Aí foi que eu fui e arrendei 100 metros de terra. Até hoje estes 100 metros de terra tá aqui! (Entrevista com Seu João, comunidade Santa Luzia da ilha do Baixio, 4/11/2011).

Na época a plantação de juta era a principal atividade desenvolvida, mas também tinham destaque plantações de milho, mandioca e feijão-de-praia, além da caça de jacaré, para a comercialização do couro, que complementava a renda das famílias. Hoje, a comunidade tem uma população estimada em 450 pessoas distribuídas em 150 famílias.

As mulheres de Santa Luzia da ilha do Baixio se dedicam principalmente ao trabalho doméstico, mas também ajudam os maridos na época da colheita e "amarram" o feijão e a cebolinha, últimos processos feitos para a venda desses produtos. Dona Páscoa, moradora antiga da comunidade, conta que tem uma 
área de roçado trabalhada pelo marido, pelo genro e por um dos filhos. Os principais produtos desse roçado são o jerimum e a melancia e por isso é difícil as mulheres ajudarem na época da colheita, pois os frutos são muito pesados. Já na família de Jeane, de 17 anos, o pai é responsável pelo roçado, mas na época da colheita todos os filhos ajudam, sejam homens ou mulheres.

Ser do gênero feminino ou masculino sempre significou perceber e estar no mundo de modos diferentes. Os sujeitos foram educados e construídos de maneiras diferentes: reprimindogestos, construindo posturas, comportamentos e movimentos. É a partir daí que se produzem as diferentes consciências do próprio corpo em homens e mulheres, e é assim que se instituem, em cada indivíduo e em toda sociedade, as relações de poder. Por relações de poder partilhamos da formulação de Foucault (1979), acerca da Microfísica do Poder:

\begin{abstract}
em qualquer sociedade, existem relações de poder múltiplas que atravessam, caracterizam e constituem o corpo social e que estas relações de gênero não podem se dissociar, se estabelecer nem funcionar sem uma produção, uma acumulação, uma circulação e um funcionamento do discurso (FOUCAULT, 1979: 179).
\end{abstract}

As mulheres participam ativamente das organizações comunitárias de Santa Luzia da ilha do Baixio. Atualmente não há nenhuma mulher no cargo de presidente ou vice-presidente da associação de produtores, mas algumas assumem funções importantes, como tesoureira. Elas também têm uma organização própria, o "Grupo de Mulheres Unidas do Baixio", que tem hoje cerca de 30 integrantes. O grupo já teve mais atuação e, atualmente, está em processo de reestruturação. Realizam encontros para debater questões da comunidade, além de produzirem artigos de artesanato para venda.

A identificação do cotidiano, tecido por seus modos de vida, pode ajudar a entender aspectos fundamentais da compreensão singular dessas mulheres sobre o território. Para Castro (2001), a compreensão da sua concepção de territorialidade só pode ser percebida no interior das relações que estruturam e organizam sua vida coletiva, e da reprodução social do grupo, no âmbito das quais as mulheres têm desempenhado historicamente papel fundamenta (Figuras 1 e 2). 

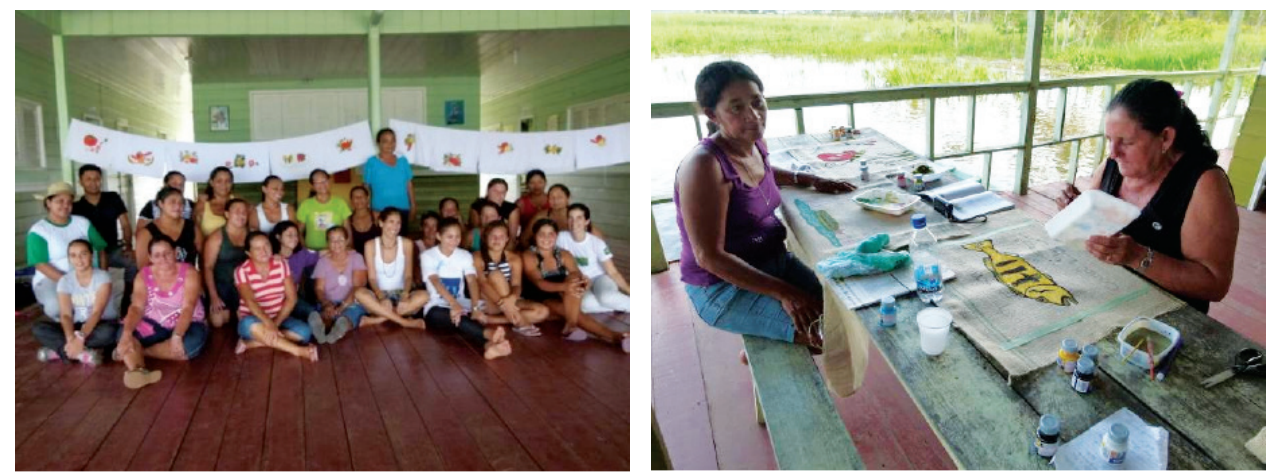

Figura 1 - Grupo de Mulheres Unidas do Baixio, em setembro de 2011.

Fonte: Oliveira, 2011.

Figura 2 - Pintura em juta para confecção de bolsas, em abril de 2012.

Fonte: Bocchini, 2011

As mulheres de Santa Luzia da ilha do Baixio vivem mantendo seus costumes tradicionais. Mas vale ressaltar que o adjetivo tradicional aliado a território não estabelece uma conexão necessária com o passado, mesmo que muitas vezes se apresente como uma recomposição de elementos trazidos do passado:

Como sustenta Sahlins (2004: 527), "a população local articula-se com a ordem cultural dominante, ao mesmo tempo que se distancia dela". Desse modo, o adjetivo "tradicional", ao invés de remetido ao passado "imemorial", aqui está referido ao presente e ao futuro, e à definição de uma Amazônia que está socialmente sendo sempre inventada (SCHWEICKARDT, 2010: 138-139).

Na década de 1980, a atividade de plantação de juta foi substituída pela plantação de produtos como couve, repolho, alface, tomate, feijão-de-corda, pimentão, coentro e cebolinha. A época do plantio das culturas varia de acordo com o tipo de hortaliça. Em geral, o plantio é feito de forma manual, utilizando ferramentas simples como enxada e terçado. O desenvolvimento da atividade agrícola relaciona-se totalmente com a dinâmica dos rios. "O manejo de terras agricultáveis está apoiado na sazonalidade das águas. As terras de várzea são consideradas de alta qualidade para plantios, desde que de ciclo 
curto" (LIMA, 2005: 195).

A comunidade, localizada em área de várzea, tem o cultivo da maioria das espécies na época da final da vazante e seca dos rios, entre julho e novembro. Os períodos de seca e cheia também são determinantes para a venda dos produtos:

Cada um tem a sua cultura. [...] Porque uns plantam um tipo de hortaliças, outros de outra, né? [...] Eu achei que teve uma melhora muito grande, no momento de venda. Porque de primeiro você tirava sua produção [...] era muito difícil para você chegar em Manaus. Principalmente agora no momento de seca, porque não tinha este ramal [...] O pessoal desperdiçava. Agora, o pessoal vem aqui na porta comprar a produção. E a gente leva para Manaus também, leva pras feiras [...]. (Entrevista com dona Fátima, comunidade Santa Luzia da ilha do Baixio, 3/11/2011).

Apesar das dificuldades relacionadas às enchentes e às dificuldades de comercialização na várzea, o ambiente é também retratado como possuidor de "riquezas", associadas ao potencial agrícola do solo, decorrente da fertilização natural pelas águas do rio. Lima, em um estudo socioambiental realizado nas várzeas dos rios Amazonas e Solimões, identifica os diversos circuitos de comercialização dos produtos agrícolas:

Para os produtos agrícolas locais (melancia, jerimum, milho, macaxeira, feijão, maracujá, banana, farinha, hortaliças) o mercado preferencial é o das sedes municipais, que dispõem de feiras semanais. Assim que os produtores chegam nas cidades (de ônibus, canoas ou barcos de linha), os compradores mais comuns são os atravessadores. Há aqueles com os quais os produtores têm conhecimento prévio e costumam contratar sua produção. Pode-se vender também para comerciantes locais, ou circulando na rua e oferecendo o produto (LIMA, 2005: 182).

A sobrevivência da família baseada na produção de hortaliças, para consumo e venda nas feiras próximas, representa um modo de vida campesino criado e recriado por meio da relação familiar e do trabalho assalariado. A 
economia camponesa

se caracteriza por formas extensivas de ocupação autônoma (trabalho familiar), pelo controle dos próprios meios de produção, economia de subsistência e qualificação ocupacional multidimensional. Se caracteriza por um ecossistema e um equilíbrio particular entre agricultura, atividade extrativista e artesanato, com uma ênfase particular no cultivo mais do que na manufatura (SHANIN, 1980: 46).

Além disso, uma vasta série de funções ocupacionais é encaixada na situação de camponês como uma ocupação, como acontece com dona Fátima:

Quando eu comecei a trabalhar, eu só tinha uma cadeira. Eu trabalhava na escola e trabalhava nas hortaliças também. Tinha uma horta. Vendia cebolinha, era [...] jambu [...] pimenta doce $[. .$.$] agora eu planto pro meu consumo,$ porque eu não tenho muito tempo, porque eu trabalho e, assim... agora eu tenho duas cadeiras na escola [...]. Eu não deixo minha horta de jeito nenhum! Eu tenho minha horta de medicina caseira e a de hortaliças (Entrevista com dona Fátima, comunidade Santa Luzia da ilha do Baixio, 3/11/2011).

O uso da policultura utilizado em Santa Luzia da ilha do Baixio é uma característica própria da agricultura familiar camponesa, "estruturado de forma a garantir a subsistência da família" (WANDERLEY, 1996: 6). A habilidade para produção agrícola está ligada à técnica tradicional, como a utilização de um calendário regido pelo pulso enchente e cheia, vazante e seca, o uso da mão de obra familiar e o processo de aprendizagem entre as gerações. Observamos, porém, que a forma tradicional de produção e trabalho não está desconectada do restante da sociedade (moderna). Muito pelo contrário, o tradicional e o moderno se relacionam constantemente, como nos momentos de venda dos produtos, nas interações com profissionais dos órgãos governamentais e não governamentais presentes na comunidade, quando complementam a renda com outros empregos, muitas vezes assalariados, entre outros exemplos de 
conexão entre a comunidade que possui um estilo de vida simples - tradicional - e a sociedade sofisticada - moderna (Figuras 3 e 4).
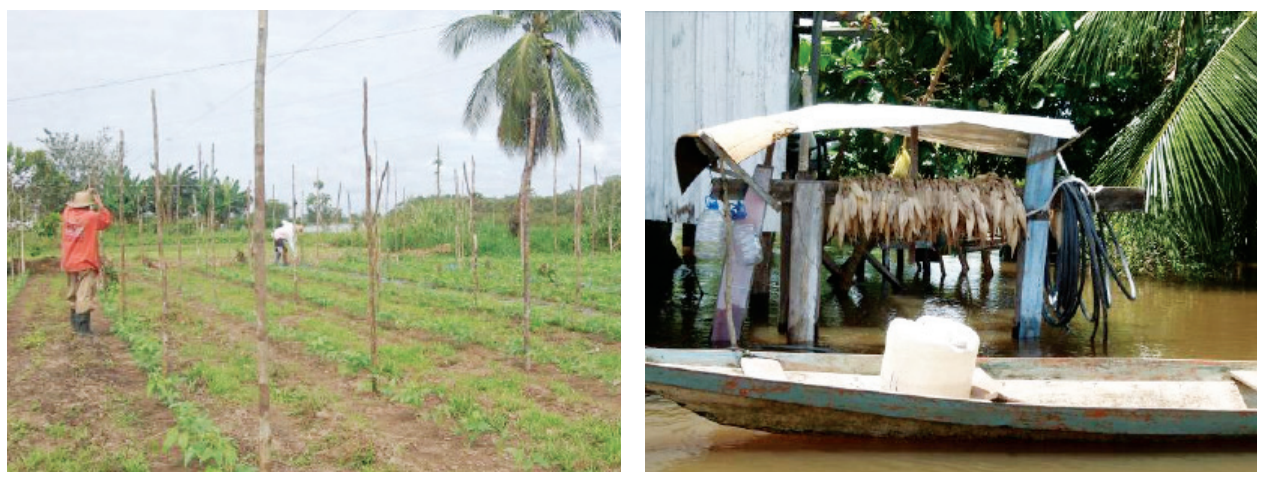

Figura 3 - Plantação de hortaliças, em março de 2012.

Fonte: Bocchini, 2012.

Figura 4 - Milhos armazenados na cheia, em abril de 2012.

Fonte: Bocchini, 2012.

\section{Educação}

A escola, em Santa Luzia da ilha do Baixio, é uma instituição importante. Tudo acontece na escola. Ela, além de atualmente oferecer os três níveis de ensino - Educação Infantil, Ensino Fundamental e Ensino Médio aos moradores da comunidade, funciona como uma espécie de centro social. Algumas reuniões das associações e todas do grupo de mulheres acontecem nas dependências da Escola Municipal Santa Luzia. A comunidade dispõe de um centro social, mas as mulheres preferem usar a escola para as reuniões. Conversando com as mulheres do "Grupo Mulheres Unidas do Baixio", elas justificam o uso da escola, e não do centro social, por causa da infraestrutura, já que tem banheiro e cozinha. É interessante analisar este fato, uma vez que a escola e o centro social são vizinhos, em uma distância de alguns passos, o que não as impediria de ir até a escola para usar o banheiro e a cozinha. $\mathrm{O}$ fato é que as mulheres não têm o sentimento de pertencimento com o centro social como têm com a escola, que faz parte de suas vidas como estudantes, professoras, funcionárias e mães de alunos (Figuras 5 e 6). Aqui fica visível a ideia de espaço físico como a retificação do espaço social e das relações sociais. 
“Em 'Efeitos de Lugar', Bourdieu (2011) sugere desconfiar das definições dos lugares construídas a partir das 'ausências', porque ao fazê-lo podemos estar evocando não 'realidades', mas fantasmas”' (SCHWEICKARDT, 2010: 93).
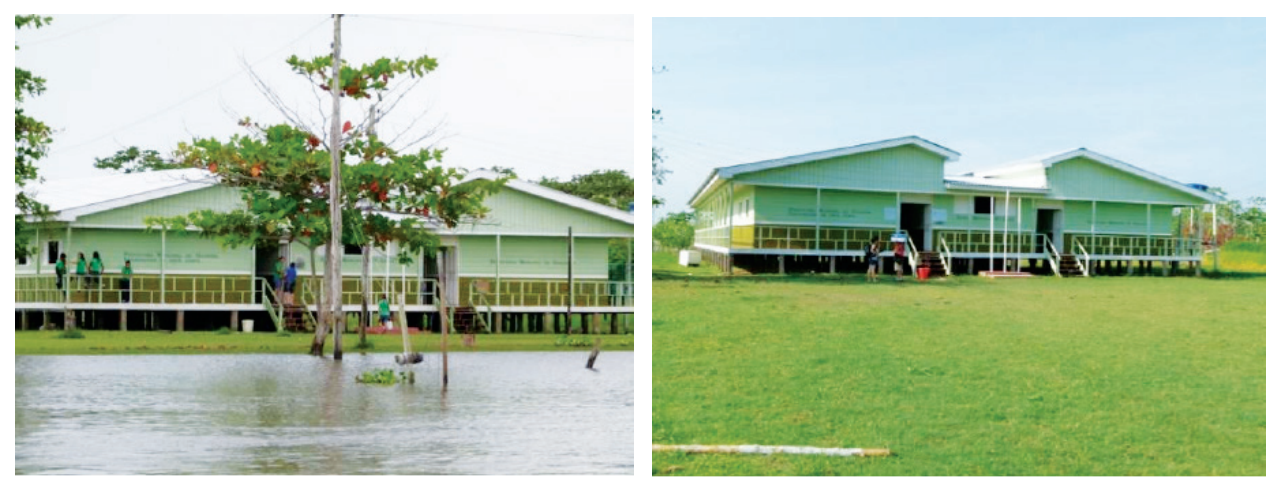

Figura 5 - Escola, em junho de 2011.

Fonte: Bocchini, 2011.

Figura 6 - Escola, em setembro de 2011.

Fonte: Bocchini, 2011.

Nos relatos ouvidos durante a realização da pesquisa, a história da escola e a história da comunidade se confundem, uma fazendo parte da outra. Por volta de 1950, os irmãos João e José - fundadores da comunidade organizaram a primeira turma da escola e pediram para dona "Nezinha" ser a professora de um grupo de crianças e adolescentes. As aulas então começaram em um flutuante que ganhou o nome de Escola São Gabriel. Com o tempo, novas turmas se formaram e as aulas eram dadas nas casas dos professores. Em 1963, já havia cerca de 50 alunos e as aulas eram dadas em paióis por duas professoras, Sr. ${ }^{\text {a }}$ Celeste Lopes e dona Páscoa:

Aí saiu uma professora e ela perguntou do meu pai se eu queria ficar trabalhando. Ele falou comigo, eu disse que ia ficar, mas eu não tinha experiência. Eu tinha só a quinta série. Mas naquela época não era preciso tanta experiência. O pessoal só queria aprender o português e a matemática, né? (Entrevista com dona Páscoa, comunidade Santa Luzia da ilha do Baixio, 14/9/2011). 
Em 1980, a prefeitura de Careiro da Várzea construiu uma escola, fase que marcou a chegada do supletivo do primeiro grau:

Eu tenho isso aí como uma vitória muito grande. Porque aqui ninguém sai pra estudar no outro canto. Nós temos professores formados aqui, gente fazendo a pós-graduação, nunca saiu daqui. E isso aí é uma vitória muito grande, porque... E eu me preocupei... do meu filho tá em uma grande cidade grande e eu tá aqui, trabalhando sozinho e ele lá. E eu não tô olhando ele, não tô sabendo o que ele tá fazendo, né? E eu já metia isso na minha cabeça, esse mundo de droga que a gente tá vivendo, esse mundo. Estamos criando nossos filhos e pra mim isso é uma coisa muito grande, dar este passo para que este povo não se deslocasse daqui. Ele (filho) trabalhava e estudava, ele me ajudava (Entrevista com Lula Filho, comunidade Santa Luzia da ilha do Baixio, 4/11/2011).

Três anos depois, em 1983, a prefeitura de Iranduba construiu outra escola, a Escola Municipal Santa Luzia, em homenagem à padroeira da comunidade. Com as constantes enchentes o prédio foi destruído e, durante oito anos, entre 1995 e 2003, a comunidade ficou sem um prédio escolar. Nesse período os alunos tinham aulas na Igreja Católica e na sede do time de futebol.

Em 2003, foi inaugurada a atual escola, que passou a funcionar nos três turnos, da Educação Infantil até a 8. ${ }^{a}$ série. Em 2006, passou a funcionar a primeira turma de Ensino Médio e, em 2007, foi implantado o Ensino Médio por intermediação tecnológica. Hoje, a escola tem 134 alunos e 14 profissionais, sendo que dez são mulheres: professoras, coordenadora administrativa, merendeira e auxiliar de serviços gerais.

A escola é uma instituição que representa muito do novo e do antigo. Hoje, existe Ensino Médio por intermediação tecnológica, com o uso de tecnologias sofisticadas e modernas e, ao mesmo tempo, sua história está vinculada à história da comunidade. Moradores e moradoras se encontram no espaço da escola para prosear, fazer assembleias, fazendo com que a escola seja também um espaço de reprodução social do modo tradicional como vivem. Ao mesmo tempo em que a escola de Santa Luzia da ilha do Baixio é um local onde a educação formal acontece, com currículos-padrão, ela também é um espaço de aprendizagem entre as diferentes gerações que circulam pelos corredores e salas da escola. Ao mesmo tempo em que os pais põem seus filhos nas escolas com vista "em um futuro melhor", o passado e a memória 
permeiam o dia a dia da escola.

A tradição também se vincula ao futuro; não um futuro concebido como algo distante e separado, e sim como uma espécie de linha contínua que envolve o passado e o presente. É a tradição que persiste, remodelada e reinventada a cada geração. Não há um corte profundo, ruptura ou descontinuidade absoluta entre o ontem, hoje e o amanhã.

\section{Saúde}

A comunidade não possui posto de saúde, contando com agentes de saúde que moram na ilha do Baixio e apenas com uma visita mensal de um médico. Com isso, as pessoas vão para Iranduba ou Manaus para realizar consultas médicas e exames:

Eu queria que tivesse um posto de saúde que pudesse atender as pessoas. Eu queria um médico frequente [...] porque agora já vem, né? [...] O médico vem de mês em mês, né? [...] Que viesse pelo menos uma vez na semana na comunidade [...]. Quando eu preciso vou pro Iranduba, ou pra Manaus. Porque o Iranduba não tem é [...] todos tipos de máquinas, de coisas assim, para fazer vários exames que precisa [...] (Entrevista com dona Fátima, comunidade Santa Luzia da ilha do Baixio, 3/11/2011).

Ao conversar com os moradores de Santa Luzia do Baixio é comum comentarem a precariedade do atendimento à saúde na comunidade. Ao mesmo tempo em que tiveram grandes conquistas em relação à educação, a atenção à saúde é quase inexistente.

Apesar de poucas pessoas cultivarem plantas medicinais, seu uso é comum. Dona Fátima é conhecida por possuir uma boa horta de plantas usadas na medicina caseira:

Eu tiro um pedaço só para eu plantar minhas plantinhas. Estas plantas medicinais que eu plantei, mana [...] eu tenho [...] é uma cultura da minha família. Meus avós, minha mãe, que me ensinaram [...] o pessoal me procura muito. [...] Tenho plantas que serve pra gastrite [...] pra [....] gripe. Outra 
pra [...] pra dor de cabeça, pra resfriado [...] pra vários tipos de doença eu tenho. Muitas pessoas vêm procurar, porque [...]. Eu acho assim, que eu puxei um pouco pra minha mãe. Porque minha mãe gostava tanto de trabalhar no roçado, como em casa (Entrevista com dona Fátima, comunidade Santa Luzia da ilha do Baixio, 3/11/2011).

O conhecimento tradicional do cultivo de plantas medicinais é passado de mãe para filha, sendo uma atividade exercida exclusivamente por mulheres:

Uma das dimensões mais importantes nas lutas dos camponeses brasileiros está centrada no esforço para constituir um "território" familiar, um lugar de vida e trabalho, capaz de guardar a memória da família e de reproduzi-la para as gerações posteriores (WANDERLEY, 1996: 11).

Além do cultivo das plantas medicinais, algumas mulheres desempenham o papel de benzedeiras e, até poucos anos atrás, de parteiras, conhecimentos estes também transmitidos através das gerações. Diferentemente do perito, o especialista da ordem social moderna, o conhecimento do guardião se reveste de mistério, se funda na pura crendice e possui um sentido místico inacessível ao comum, ao leigo:

A tradição é impensável sem guardiões, porque estes têm um acesso privilegiado à verdade; a verdade não pode ser demonstrada, salvo na medida em que se manifesta nas interpretações e práticas dos guardiões. O sacerdote, ou xamã, pode reivindicar ser não mais que o porta-voz dos deuses, mas suas ações de facto definem o que as tradições realmente são. As tradições seculares consideram seus guardiões como aquelas pessoas relacionadas ao sagrado (GIDDENS; BECK; LASH, 1997: 100).

\section{Construções}

Todas voltadas para o rio, as construções - casas, igreja, escola, campo de futebol - são distribuídas linearmente. No centro encontramos o campo de 
futebol e a casa de Seu João, fundador da comunidade. À esquerda do campo há a Igreja Católica e, à direita, a escola e o centro social, respectivamente. As casas mais próximas dessa área central, à direita, são do diretor da escola, professor Valdir, e do presidente da comunidade, "Deca", casado com Valdiza, líder do grupo de mulheres. Já à esquerda as casas mais próximas são da família de Edivaldo, filho do falecido Seu José, também fundador da comunidade. Nota-se que as casas mais próximas do centro da comunidade são das famílias consideradas mais importantes, aquelas que possuem membros fundadores da comunidade e representantes da escola e da associação.

Como o padrão nas áreas de várzea da Amazônia, as casas de Santa Luzia da ilha do Baixio são de madeira e palafita, suspensas de forma a suportar a sazonalidade das águas. O banheiro fica fora da casa e, em alguns casos, a cozinha também. Nos quintais, são comuns as pequenas hortas utilizadas para o consumo da família e a criação de pequenos animais, como galinhas e patos, além de cachorros como animais domésticos. Muitas casas têm varanda, lugar onde costumam receber visitas:

A organização espacial da casa, com a definição dos lugares das mulheres e dos homens, assim como a associação ritual dos diferentes lugares da casa com ciclos biológicos como fecundidade, fertilidade, lugar dos animais, aquilo que é da natureza, em oposição aos lugares de cozinhar e do tear, lugar de receber as visitas, aquilo que é da cultura, revelam também a oposição entre homens e mulheres e entre a vida privada e a vida pública (SCHWEICKARDT, 2010: 331).

As pessoas que moram na mesma casa formam o grupo doméstico, sendo então a casa o espaço físico que representa a família, característica central do campesinato. Uma nova casa é, em geral, construída a partir da constituição de um novo casal. "A nova casa materializa a formação de uma nova unidade doméstica, que permite a reprodução física e social da família de pequenos produtores" (GARCIA JR., 1983: 160). Podemos dizer que é a partir da casa - da família - que o camponês se articula com a sociedade, que organiza o mundo social (Figuras 7 e 8). A casa é definida por Garcia Jr. como espaço de reprodução: 
Quando aqui estamos nos referindo à casa como local de reprodução, não estamos apenas falando dos elementos materiais que compõem esta reprodução (como comida, por exemplo), mas que tal é o local onde são reproduzidas as regras e formas sociais de existência do grupo, isto é, sua ideologia (GARCIA JR., 1983: 164).
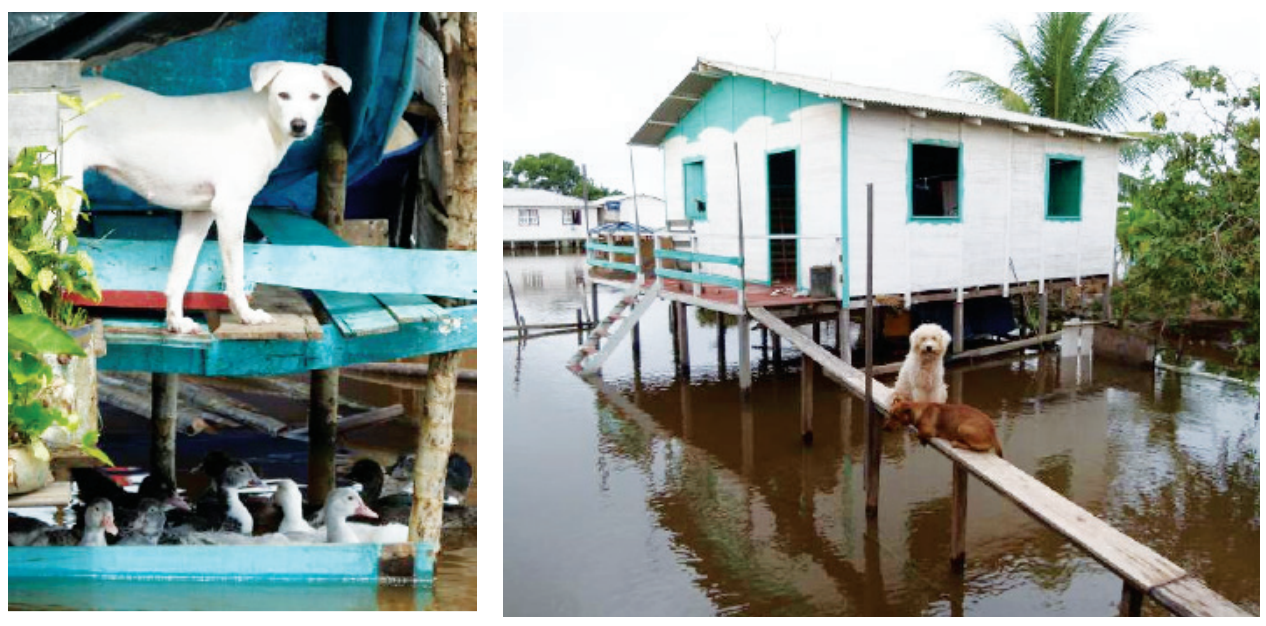

Figuras 7 e 8 - Animais na área externa da casa na época da cheia.

Fonte: Bocchini, abril de 2012.

Recentemente, em 2007, a ilha do Baixio foi transformada, por meio do Instituto Nacional de Colonização e Reforma Agrária - Incra - em um Projeto de Assentamento Agroextrativista - PAE - que teve como principal benefício à população a aplicação do Crédito Habitação da reforma agrária, que vem implantando e reformando as casas (Figuras 9 e 10).

A "casa do Incra", como é conhecida localmente e em outras calhas de rio onde a mesma iniciativa foi implantada, mesmo sendo fruto de uma política pública e, como tal, de uma ação do Estado, configura-se como a materialização das conquistas dos camponeses da Amazônia. Embora os recursos da reforma agrária tenham sido negociados por agentes públicos e instâncias governamentais do Estado, Incra e o Serviço de Patrimônio da União - SPU -, a aplicação dos créditos e o controle dos recursos são feitos junto à organização local dos moradores do PAE. Seu Edivaldo é carpinteiro e construiu a maioria das "casas do Incra": 

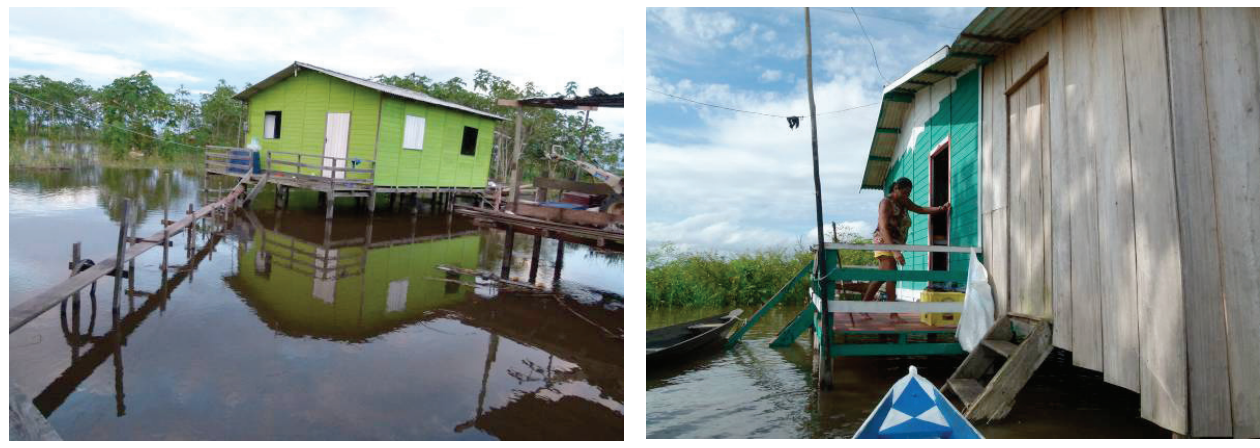

Figura 9 - "Casa do Incra" em Santa Luzia da ilha do Baixio.

Fonte: Bocchini, 2012.

Figura 10 - "Casa do Incra", ampliada, em Santa Luzia da ilha do Baixio.

Fonte: Bocchini, 2012.

Esse é um projeto do governo, né? Esse assentamento que foi criado aqui, pros moradores. [...] É uma casinha pequena, mas é muito bom, serve pra [...] eu sou tudo pago pelo Incra, pra construir essas casa aí (Entrevista com Seu Edivaldo, comunidade Santa Luzia da ilha do Baixio, 4/11/2011).

\section{Relação com o mundo urbano}

Por se encontrar a apenas $15 \mathrm{~km}$ de Iranduba e $25 \mathrm{~km}$ de Manaus, as pessoas que vivem em Santa Luzia da ilha do Baixio têm uma relação estreita com essas duas cidades. Como já observamos anteriormente, principalmente por motivos de saúde e para comercialização dos produtos (e pouco tempo atrás para estudarem), as pessoas se deslocam para as cidades. $\mathrm{Na}$ época de cheia dos rios utilizam barcos de linha ou tipo voadeiras para irem a Iranduba ou a Manaus. Há aqueles que vão até Iranduba e, de lá, pegam ônibus para Manaus. Na época da seca, há um ônibus de linha que vai do centro de Iranduba até a comunidade. Nessa época as pessoas se locomovem muito mais por meio de carros, motos e ônibus.

Em outubro de 2011, foi inaugurada em Manaus a ponte sobre o rio Negro, que é vista pela comunidade com bons olhos. Antes, para irem a Manaus, enfrentavam uma longa espera para pegar a balsa. Esta ponte, que tá dando este sucesso todo, esse comentário no mundo inteiro. E saiu. Graças a Deus saiu essa 
ponte! (Entrevista com Lula Filho).

Em novembro, Santa Luzia da ilha do Baixio organiza, faz cinco anos, a Festa das Hortaliças. A maioria dos moradores se envolve na organização: homens, mulheres e jovens passam a semana que antecede a festa trabalhando na arrumação da comunidade, fabricando enfeites para ornamentação e preparando comidas para venda. A sede da organização da festa é a escola. É lá que as mulheres preparam comidas e os jovens cuidam da ornamentação. Os homens se dedicam mais ao "trabalho pesado" no campo de futebol, mas eles também têm como ponto de encontro o espaço da escola. Esse é momento do ano em que a comunidade recebe o maior número de visitantes: pessoas que vêm de Manaus, Iranduba e comunidades da região.

$\mathrm{Na}$ ornamentação da V Festa das Hortaliças, que ocorreu em 2011, havia duas maquetes: uma representando a comunidade nas décadas de 50 e 60 e outra como a comunidade é atualmente. Foi feito também um painel representando Manaus e a ponte sobre o rio Negro, ligando a capital à ilha do Baixio. Na ponte da maquete havia caminhões indo da comunidade para Manaus com hortaliças em suas caçambas. Um professor da comunidade também expôs dois poemas: um sobre a ponte e outro sobre a balsa. A ponte simbolizando a chegada da modernidade, da melhora de vida para a população de Iranduba e, mais especificamente, para aqueles que vivem em Santa Luzia da ilha do Baixio e terão mais facilidade para escoarem seus produtos. A balsa, como algo que fez parte da vida daquelas pessoas, deixará saudades.

\section{De Manaus para o Iranduba}

De Manaus para o Iranduba

Manacapuru e Novo Airão

e para todos os municípios

que compõem essa região

uma ponte foi construída

fazendo a integração.

Estrutura estaiada

arquitetura que evoluiu

um lado e outro se encontram, 
como torre no meio do rio,

hoje podemos dizer

é a mais bonita do Brasil.

Belas paisagens os olhos verão, do alto tanta beleza, de um lado Manaus tão linda, com sua orla e a Ponta Negra do outro o nosso Iranduba com o verde da natureza.

Iranduba tão orgulhosa natureza que a todos encanta, e agora recebe essa obra, uma ponte muito bacana, por ser tão perto de Manaus é área metropolitana.

Nas idas e vindas do povo o transporte vai melhorar quem vai em busca de compra, quem vai só para trabalhar, quem vem nos finais de semana no Iranduba passear.

Parabéns ao produtor deste vasto beiradão que produz muitas hortaliças e ganhou mais uma opção de chegar rápido a Manaus e vender a sua produção.

Quem chegou aqui nesta festa, de qualquer lugar do Brasil, quem veio por esta ponte, passando por cima do rio, 
que todos sejam bem-vindos, ao nosso querido baixio.

Cortando as águas do Negro, teus pilares foram erguidos, concreto e ferro mostrando a grandeza desse sonho lindo, surgindo do fundo das águas, transformando-se em grandes cilindros.

\section{Adeus, querida balsa}

Adeus, querida balsa,

De tantas travessias

Tu levavas e trazias

Tanta gente todo dia.

Vai navegar por outras águas ou repousar num estaleiro, transportaste tantos ricos

e quem não tinha dinheiro. Por quase quarenta anos tu servias todo mundo. Devagar mas tu chegavas, do Cacau ao São Raimundo.

Jamais te esqueceremos. Ficarás em nossa memória com a ponte tão moderna,

Para nós tu és história.

Adeus!

Essa relação da comunidade com o município de Iranduba e a capital Manaus, de um lado, os moradores de Santa Luzia indo a Manaus para a venda 
de produtos, para passear nos finais de semana e, de outro, ao receber pessoas das duas cidades na comunidade, representa uma troca de experiências, vivências e saberes. Essa troca é denominada por Therezinha Fraxe (2004) como transculturalidade, aquilo que gera mudanças e adaptações no estilo de vida, tanto urbano como rural. Costumes antigos, festejos, técnicas de extrativismo, mitos, histórias, alimentação típica se misturam com informações que vêm desse vaivém entre a comunidade e os municípios.

\section{Considerações finais}

Tradição e modernidade são concebidas, muitas vezes, como noções ou mesmo momentos históricos sucessivos, opostos, incompatíveis e mutuamente excludentes, já que a realização do moderno implicaria na eliminação, mais ou menos abrupta, do tradicional.

O conceito de modernidade refere-se a um estilo de vida que emergiu na Europa, a partir do século 17, e que depois se tornou mais ou menos comum em outras localidades do mundo. Atualmente a modernidade é vista por alguns autores da sociologia como fatigada em suas possibilidades de realização histórica, como se tivesse chegado a seu fim, cedendo lugar ao chamado pós-modernidade. Alguns autores, entretanto, preferem designar o momento da modernidade em sua contemporaneidade, guiada por um conjunto de elementos sociais, culturais, econômicos e ambientais bastante próprios como desdobramento da própria modernidade. Salienta-se, no entanto, que não há dúvida da existência de uma "crise" da modernidade, mas não se assume a perspectiva de que ela já se tenha sido esgotada como se fosse um projeto acabado. Anthony Giddens diz que: "Em vez de estarmos entrando num período de pós-modernidade, estamos alcançando um período em que as consequências da modernidade estão se tornando mais radicalizadas, universalizadas do que antes" (GIDDENS, 1991: 13). A essa categoria denominaremos modernidade extensiva.

A modernidade extensivanão possui formas homogêneas de desenvolvimento. Nessa perspectiva, Giddens identifica três formas de descontinuidades que separam as instituições modernas das ordens sociais tradicionais:

Uma é o ritmo de mudança nítido que a era da modernidade 
põe em movimento. As civilizações tradicionais podem ter sido consideravelmente mais dinâmicas que outros sistemas pré-modernos, mas a rapidez da mudança em condições de modernidade é extrema. (...) Uma segunda descontinuidade é o escopo da mudança. Conforme diferentes áreas do globo são postas em interconexão, ondas de transformação social penetram através de virtualmente toda a superfície da Terra. Uma terceira característica diz respeito à natureza intrínseca das instituiçoes modernas. [...] Tais como o sistema político do estado-nação, a dependência por atacado da produção de fontes de energia inanimadas, ou a completa transformação em mercadoria de produtos e trabalho assalariado (GIDDENS, 1991: 15-16).

As sociedades modernas são, portanto, sociedades de mudança constante e rápida, em contraposição com o que se entende por tradicional. "Porém existem continuidades entre o tradicional e o moderno, e nem um nem outro formam um todo à parte" (GIDDENS, 1991: 14). Portanto, devemos nos atentar a essa distinção entre moderno e tradicional, uma vez que ambos vivem, hoje, em formas de continuidade e descontinuidade, de encaixe e desencaixe.

Por desencaixe, Giddens se refere ao deslocamento das relações sociais de contextos locais de interação e sua reestruturação por meio de extensões indefinidas de tempo-espaço. Grupos sociais considerados ainda hoje como tradicionais também estão envolvidos nos contextos modernos de rápidas mudanças:

[...] muitas combinações do moderno e do tradicional podem ser encontradas nos cenários sociais concretos. Na verdade, alguns autores têm argumentado que ambos estão tão cerradamente entrelaçados que qualquer comparação generalizada não é válida (GIDDENS, 1991: 43).

Nota-se que as populações ditas tradicionais vivem seu dia a dia não em um contexto isolado, mas articuladas às ordens culturais dominantes. Existe no cotidiano desses povos a influência da cultura moderna sobre a tradicional e vice-versa. O termo tradicional sempre nos remete ao passado, a aquilo que é praticado por um grupo social da mesma maneira, há muitos anos. A tradição, porém, 
é uma maneira de lidar com o tempo e o espaço, que insere qualquer atividade ou experiência particular dentro da continuidade do passado, presente e futuro, sendo estes por sua vez estruturados por práticas sociais recorrentes. A tradição não é inteiramente estática, porque ela tem que ser reinventada a cada nova geração conforme esta assume sua herança cultural dos precedentes. A tradição não só resiste à mudança como pertence a um contexto no qual há, separados, poucos marcadores temporais e espaciais em cujos termos a mudança pode ter alguma forma significativa (GIDDENS, 1991: 44).

Dessa forma a tradição, se por um lado se refere a uma resistência à mudança, mantendo modos antigos de se viver, por outro está diretamente ligada ao contexto de tempo e espaço em que se vive. Percebemos, na breve descrição etnográfica realizada em Santa Luzia da ilha do Baixio, que as relações sociais existentes na história da comunidade, na agricultura familiar, na educação, na saúde, nas construções, nas festas e nas relações com o "mundo urbano", evidenciam a existência de uma cultura tradicional, com um modo de vida campesino, entrelaçadas com a modernidade, em um processo constante de ressignificação do modo de vida tradicional. Tradição e modernidade se combinam e se interpenetram como termos contrários e ao mesmo tempo complementares, ainda que de modo descontínuo, multifacetado, híbrido.

\section{Notas}

1 Relativizar é uma atitude epistêmica, eminentemente antropológica, graças à qual o pesquisador logra escapar da ameaça do etnocentrismo - essa forma habitual de ver o mundo que circula o leigo, cuja maneira de olhar e de ouvir não foram disciplinados pela antropologia (CARDOSO DE OLIVEIRA, 2000: 33).

\section{Referências}

BOURDIEU, Pierre. A miséria do mundo. 8. ed. Petrópolis, RJ: Vozes, 2011. . Coisas ditas. São Paulo: Brasiliense, 2004.

CARDOSO DE OLIVEIRA, Roberto. O trabalbo do antropólogo. 2. ed. Brasília: 
Paralelo 15; São Paulo: Editora da Unesp, 2000.

CASTRO, Edna. "Prefácio". In: SIMONIAN, Lígia. Mulheres da floresta amazônica: entre o trabalho e a cultura. Belém: UFPA / Naea, 2001.

CLIFFORD, James. Sobre a autoridade etnográfica. In: GONÇALVES, José Reginaldo Santos (Org.). A experiência etnográfica: antropologia e literatura no século XX. Rio de Janeiro: Editora da UFRJ, 1998.

FOUCAULT, Michel. Microfísica do poder. Rio de Janeiro: Graal, 1979.

FRAXE, Therezinha de Jesus Pinto. Cultura caboclo-ribeirinha: mitos, lendas e transculturalidade. 2. ${ }^{a}$ ed. São Paulo: Annablume, 2004.

GARCIA JR., Afrânio Raul. Terra de trabalho: Trabalho Familiar de Pequenos Produtores. Rio de Janeiro: Paz e Terra, 1983.

GEERTZ, Clifford. Uma descrição densa: por uma Teoria Interpretativa da Cultura. In: A interpretação das culturas. Rio de Janeiro: Livros Técnicos e Científicos Editora S/A., 1989.

GIDDENS, Anthony. As consequências da modernidade. São Paulo: Editora da Universidade Estadual Paulista, 1991.

.; BECK, U; LASH, S. Modernização Reflexiva: política, tradição e estética na ordem social. São Paulo: Editora da Unesp, 1997.

LIMA, Deborah (Org.). Diversidade socioambiental nas várzeas dos rios Amazonas e Solimões: perspectivas para o desenvolvimento da sustentabilidade. Manaus: Ibama, ProVárzea, 2005.

SCHWEICKARDT, Kátia Helena S. C. As diferentes faces do Estado na Amazônia: etnografia dos processos de criação e implantação da Resex Médio Juruá e da RDS Uacari no Médio Rio Juruá. 2010. Tese (Doutorado em Sociologia e Antropologia). Universidade Federal do Rio de Janeiro, Rio de Janeiro, 2010.

SCOTT, Joan. Gênero: uma categoria útil de análise histórica. Educação e Realidade: mulher e educação. Porto Alegre, v. 15, n. ${ }^{\circ}$ 2, jul./dez., 1991, p. 11-38. SHANIN, Theodor. A definição de camponês: conceituações e desconceituações: o velho e o novo em uma discussão marxista. Estudos Cebrap, n. 26 , Editora Vozes, 1980. 
WANDERLEY, Maria de Nazareth Baudel. Raízes históricas do campesinato brasileiro. In: XX Encontro anual da Anpocs G17. Processos sociais agrários. Caxambu, Minas Gerais, 1996. 